\title{
Expression profiling of dipeptidyl peptidase 8 and 9 in breast and ovarian carcinoma cell lines
}

\author{
CLAIRE H. WILSON ${ }^{1,2}$ and CATHERINE A. ABBOTT ${ }^{1}$ \\ ${ }^{1}$ School of Biological Sciences, Flinders University, Adelaide, South Australia, Australia
}

Received March 27, 2012; Accepted May 4, 2012

DOI: $10.3892 /$ ijo.2012.1522

\begin{abstract}
Proteases, particularly serine proteases like dipeptidyl peptidase 4 (DP4) and fibroblast activation protein (FAP), play an important role in cancer invasion and angiogenesis. Aberrant expression of DP4 and FAP is associated with numerous cancers, including breast and epithelial ovarian carcinoma. We investigated the mRNA levels, protein expression and enzyme activity of the structural homologs DP8 and DP9, in addition to DP4 and FAP, in three breast carcinoma (MDA-MB-231, MDA-MB-453, MCF-7), three epithelial ovarian carcinoma (EOC) (OVCA-432, OVCA-429, SKOV3), 293T and HeLa cell lines. In addition, DP2 and prolyl endopeptidase (PEP) mRNA and enzyme levels were measured and compared in each cell line. Ubiquitous but differential expression of DP8 and DP9 mRNA and protein was observed across all cell lines. Relative to EOC, DP8 protein was lower in the breast carcinoma cell lines $(\mathrm{p}=0.057)$, suggesting that DP8 may play differing roles in different cancer cell types. A strong, negative, non-reciprocal relationship was identified between DP9 protein and DP4 mRNA $(r=-0.903, p=0.002)$ and protein $(\mathrm{r}=-0.810, \mathrm{p}=0.015)$. This suggests that DP4 expression plays an important role in the post-transcriptional regulation of DP9 in breast and ovarian cancer cell lines. Overall, this study suggests a potential role for DP8 and DP9 in breast and ovarian cancer and further investigations in this area are required.
\end{abstract}

Correspondence to: Dr Claire Wilson, ${ }^{2}$ Present address: Centre for Cancer Biology, SA Pathology, Adelaide SA, Australia

E-mail: claire.wilson2@health.sa.gov.au

Abbreviations: CLL, chronic lymphocytic leukemia; DP, dipeptidyl peptidase; EOC, epithelial ovarian carcinoma; ERc, estrogen receptor; ESFT, Ewing's sarcoma family of tumors; FAP, fibroblast activation protein; GLP, glucagon-like peptide; HER2, human epidermal growth factor receptor 2; NPY, neuropeptide Y; PEP, prolyl endopeptidase; SDF-1, stromal derived factor-1

Key words: dipeptidyl peptidase, epithelial ovarian cancer, breast cancer, DP8, DP9, DP4, expression

\section{Introduction}

Breast and ovarian cancer are two of the most common and lethal cancers affecting women worldwide. Estimates rank breast cancer as being the number one cause of new cancer cases $(1,383,000$ cases, $22.9 \%)$ and cancer related deaths $(458,000$ deaths, $13.7 \%)$ in women worldwide in 2008. Ovarian cancer was ranked as the seventh cause of new cancer cases (225,000 cases, $3.7 \%)$ and cancer related deaths $(140,000$ deaths, $4.2 \%)$ in women worldwide in the same year (1). Among gynecological malignancies, epithelial ovarian carcinoma (EOC) is the most lethal to women in the world, accounting for approximately $90 \%$ of all tumors affecting the ovaries (2). Mortality from breast cancer often results from distant metastatic spread to lung, bone and lymph node tissue while diagnosis of EOC typically occurs in the late stages of disease after its spread into the peritoneal cavity or other distant sites (2), thus making it difficult for effective treatment to be administered. Although a number of risk factors for the development of breast and ovarian cancer have been identified the exact origin and pathogenesis of disease is still poorly understood $(3,4)$. Increasing our knowledge about the fundamental biology of these diseases is needed for the development of improved diagnostic, prognostic and therapeutic interventions at all stages of disease.

Enzymatic members of the DP4-like gene family, DP4, FAP, DP8 and DP9, share the rare ability to cleave N-terminal dipeptides at post-proline bonds in the penultimate position and play an important role in the biological processing of the N-termini of peptides such as chemokines, glucagonlike peptide (GLP)-1, GLP-2 and neuropeptide Y (NPY) (5-8). Many of these substrates, particularly chemokines, are involved in cancer remodeling and tumor progression (5-8). Notably, the chemokine CXC12 [stromal derived factor 1 (SDF-1)], a known endogenous DP4 substrate (9) which is also cleaved by DP8 in vitro (7) and its receptor, CXCR4, form a CXC12/CXCR4 axis that appears to play an important role in tumor cell proliferation and metastases of numerous cancers including breast and epithelial ovarian cancer (10-12). DP4 proteolysis inactivates SDF- $1 \alpha / \beta$, disrupting the SDF-1/ CXCR4 interaction affecting downstream signaling and the likely SDF-1 mediated cell migration and metastasis (13-15). DP4, DP8 and DP9 have recently been shown to act as survival factors for Ewing's sarcoma family of tumors (ESFT) through the inactivation of NPY-driven cell death within ESFT cells 
(16). There also appears to be non-enzymatic functions of DP4, FAP, DP8 and DP9 that are important to their roles affecting migration, proliferation and apoptosis of tumor cells $(17,18)$.

Aberrant expression of DP4 and FAP is observed in many cancers, including breast and ovarian carcinoma, and their level of expression appears to contribute to their conflicting roles in these diseases (reviewed in ref. 19). In animal models of breast cancer, the expression of DP4 at high levels appears to have a tumor promoter effect (20-22) while overexpression of DP4 in EOC appears to have a tumor suppressor effect $(23,24)$. When DP4 is highly expressed on the surface of rat lung capillary endothelial cells it can function as an adhesion receptor for rat breast cancer cells, aiding lung metastasis $(20,21)$. In addition, in Fischer 344/CRJ rats, which express low levels of an enzymatically inactive DP4 mutant on the surface of rat lung endothelium, there is a $33 \%$ reduction in lung metastasis following inoculation with rat MTF7 breast cancer cells (22). In contrast, overexpression of DP4 in human EOC results in a decreased migratory and invasive potential of the cells in vitro and decreased tumor load with increased survival in vivo (23). Overexpression of DP4 in EOC has also been associated with enhanced chemosensitivty to paclitaxel (24), a chemotherapeutic commonly used in combination with a platinum-based chemotherapy such as cisplatin for the treatment of EOC and breast cancer. FAP, not commonly present in normal adult tissues, is highly expressed in over $90 \%$ of human epithelial tumors including breast and ovarian tumors (25) and enzymatically active FAP is present in human breast and ovarian carcinoma tissues (26). In the tumor microenvironment of transgenic mice, FAP-expressing stromal cells have a major immunosuppressive effect that helps promote tumor growth and survival (27). However, aberrant expression of FAP is associated with differing tumorigenic properties in breast cancer. Elevated expression of FAP is observed in invasive ductal carcinoma cells of human breast cancer tissue, cells from lymph node metastases (28) and has been associated with pro-longed breast cancer-patient survival (29). Knockdown of FAP in human breast carcinoma cell lines decreases tumorigenic properties of cells (30) while overexpression of FAP has been shown to increase tumor growth and angiogenesis (31). This research is contradictory suggesting that FAP is functioning as a tumor promoter in breast cancer while increasing patient survival. Therefore, the exact levels of FAP expression may be important. Some in vivo evidence demonstrates that the level of expressed FAP is associated with its metastatic potential. Inoculation of immunosuppressed Balb/ $\mathrm{c}^{\text {nu/nu }}$ mice with high, medium and low FAP expressing SB247 ovarian cancer cell lines revealed a decrease in metastasis in the low-expressing FAP cells (32). Thus in animal models of ovarian carcinoma increased FAP expression results in tumor progression.

DP8 and DP9 are ubiquitously expressed at the mRNA level in all normal human adult and neonatal tissues (33-35). However, information on the expression of DP8 and DP9 in pathophysiological settings and potential roles in cancer is limited. In contrast to the recently identified NPY-dependent survival role suggested for DP8/DP9 in Ewings sarcoma (16), the overexpression of DP8 and DP9 in HEK293T and HepG2 cells has been shown to increase migration, proliferation and enhance staurosporine-streptomyces induced apoptosis $(17,36)$ suggesting the effects of DP8/DP9 in cancer, like DP4 and FAP, may be tumor specific. In chronic lymphocytic leukemia (CLL) a significant increase in DP8 mRNA has been observed (37) while upregulation of DP9 mRNA has been observed in testicular cancer (38). In human meningiomas, DP8 and DP9 have a higher level of mRNA and protein expression, relative to DP4 and FAP, and DP8/DP9 were identified as the enzymes responsible for the majority of DP activity observed (39). In contrast, in human gliomas DP4 was found to be the predominant enzyme and not DP8 or DP9 (40). Altered expression levels of DP8 and DP9, either alone or in relation to DP4 and FAP, are yet to be investigated in other cancers including breast and ovarian cancer.

Expression profiling of the DPs in breast and ovarian cancer cell lines will help further our understanding of the contribution of this family and their molecular mechanisms to breast and ovarian tumorigenesis. DP2 and prolyl endopeptidase (PEP) are also Clan SC serine proteases but are not members of the DP4-like gene family. DP2 is an exopeptidase and PEP is an endopeptidase. Both are capable of cleaving post-prolyl bonds and as such many DP inhibitors can also inhibit their activity. For this reason in this study we also investigated the expression of DP2 and PEP to help delineate the roles of DP8, DP9, DP4 and FAP in these cell lines. Here we provide the first study into the expression and activity of DP8 and DP9, in context with DP4 and FAP in breast and ovarian cancer cell lines.

\section{Materials and methods}

Cell culture. Cell lines used in this study are as follows: three human breast epithelial cancer cell lines, MCF-7 and MDA-MB231, both originally derived from pleural effusion (PE) of breast adenocarcinoma and MDA-MB-453 originally derived from PE of metastatic breast cancer; three human EOC cell lines, OVCA-432, OVCA-429 and SKOV3, originally derived from ascites of metastatic EOC tissue; the human kidney epithelial cell line, 293T and the human cervical epithelial cancer cell line, HeLa derived from cervical adenocarcinoma. MCF-7, MDA-MB-231, MDA-MB-453, OVCA-432 and SKOV3 cell lines were maintained in RPMI-1640 supplemented with $10 \%$ FBS, 100 units/ml penicillin, and $100 \mu \mathrm{g} / \mathrm{ml}$ streptomycin (Invitrogen). OVCA-429, 293T and HeLa cell lines were maintained in DMEM high glucose $(4,500 \mathrm{mg} / \mathrm{l}$ glucose) supplemented with $10 \%$ FBS, 100 units/ml penicillin, and $100 \mu \mathrm{g} / \mathrm{ml}$ streptomycin. Characteristic features of these cell lines are outlined (Table I).

RNA isolation and real-time quantitative PCR ( $q P C R)$. Total RNA was isolated from $0.5-1 \times 10^{7}$ cells by a combination of the TRIzol ${ }^{\circledR}$ reagent (Invitrogen) reagent method and the RNAqueous ${ }^{\circledR}$ kit (Qiagen) with on-column DNase I (Invitrogen) digestion. Complementary DNA (cDNA) was synthesized from $5 \mu \mathrm{g}$ of total RNA using $0.5 \mu \mathrm{g}$ of Oligo(dT) $)_{15}$-primer (Roche Diagnostics) and SuperScript ${ }^{\circledR}$ III Reverse Transcriptase (Invitrogen) as per the manufacturer's instructions. Quantitative measurements of DPs and PEP mRNA levels were determined by real-time qPCR using TaqMan ${ }^{\mathrm{TM}}$ probe technology and external PCR product standards of known copy number. Primer and probe sequences used for DP8, DP9, DP4, FAP, 
Table I. Characteristics of breast and ovarian cancer cell lines used in study.

\begin{tabular}{|c|c|c|c|}
\hline Cell type & Name & Characteristics & References \\
\hline \multirow[t]{3}{*}{ Breast cancer } & MCF-7 & $\begin{array}{l}\text { Weakly invasive; positive for ERc } \alpha \text { expression; } \\
\text { expresses insulin-like growth factor binding protein } \\
\text { (IGFBP) }-2,-4 \text { and }-5 \text {; expresses WNTB7 oncogene }\end{array}$ & $\begin{array}{l}(\text { ATCC\# HTB-22) } \\
(41,42)\end{array}$ \\
\hline & MDA-MB-231 & $\begin{array}{l}\text { Highly invasive; negative for ERc } \alpha \text { expression; } \\
\text { expresses EGFR, TGF } \alpha \text { and the WNT7B oncogene }\end{array}$ & $\begin{array}{l}\text { (ATCC\# HTB-26) } \\
(42)\end{array}$ \\
\hline & MDA-MB-453 & $\begin{array}{l}\text { Weakly invasive; negative for ERc } \alpha \text { expression; } \\
\text { negative for expression of EGFR; expresses FGFR receptor }\end{array}$ & $\begin{array}{l}\text { (ATCC\# HTB-131) } \\
(42,43)\end{array}$ \\
\hline \multirow[t]{3}{*}{ Ovarian cancer } & OVCA-432 & $\begin{array}{l}\text { Expresses lower levels of HER2 receptor compared to SKOV3; } \\
\text { positive for ERc } \alpha \text { expression; expresses EGFR }\end{array}$ & $(44-46)$ \\
\hline & OVCA-429 & $\begin{array}{l}\text { Expresses lower levels of HER } 2 \text { receptor compared to SKOV3; } \\
\text { positive for ERc } \alpha \text { expression }\end{array}$ & $(44,46)$ \\
\hline & SKOV3 & $\begin{array}{l}\text { Over-expresses HER2; positive for ERc } \alpha \text { expression } \\
\text { but unresponsive to stimulus; }\end{array}$ & $\begin{array}{l}(\text { ATCC\# HTB-77) } \\
(45-47)\end{array}$ \\
\hline \multirow[t]{2}{*}{ Other } & $293 \mathrm{~T}$ & $\begin{array}{l}\text { Routinely/widely used cell line; highly transfectable; } \\
\text { expresses SV40 T antigen (temperature sensitive gene) }\end{array}$ & (ATCC\#CRL-11268) \\
\hline & HeLa & $\begin{array}{l}\text { Express EGFR; HPV } 18 \text { positive; widely considered to be } \\
\text { negative for ERc } \alpha \text { expression but positive expression } \\
\text { has been detected by some }\end{array}$ & $\begin{array}{l}(\mathrm{ATCC \# CCL-2)} \\
(48,49)\end{array}$ \\
\hline
\end{tabular}

ATCC\#, American tissue culture catalog number; EGFR, epidermal growth factor receptor; ERc $\alpha$, estrogen receptor $\alpha$; FGFR, fibroblast growth factor receptor; HER2, human epidermal growth factor receptor 2; HPV, human papillomavirus; SV40, simian virus 40; IGFBP, insulinlike growth factor binding protein TGF $\alpha$, transforming growth factor $\alpha$.

DP2 and PEP are the same as previously published (37). The hypoxanthine ribosyltransferase 1 (HPRT1) house-keeping primer sequences were as previously published (50). Each PCR reaction $(12.5 \mu \mathrm{l})$ contained: 0.5 units Platinum ${ }^{\circledR}$ Taq (Invitrogen, Carlsbad, CA, USA), 1X High Fidelity Platinum Taq buffer (Invitrogen), $3 \mathrm{mM} \mathrm{MgCl}_{2}$ for DP8, DP9, DP4, FAP and HPRT1 amplification or $2 \mathrm{mM} \mathrm{MgCl}_{2}$ for DP2 and PEP amplification, $0.2 \mathrm{mM}$ dNTPs (Fisher Scientific, WA, Australia) $50 \mathrm{ng}$ each of forward and reverse primers, $200 \mathrm{nM}$ probe and $15.625 \mathrm{ng}$ of cDNA or $10^{7}-10^{2}$ copies of external PCR standard. Quantitative real-time PCR reactions were run in a Rotorgene 3000 (Corbette Research/Qiagen, CA, USA). Cycling conditions were as follows: Step 1,1 cycle of $94^{\circ} \mathrm{C}$ for $2 \mathrm{~min}$; Step 2, 40 cycles of $\left[94^{\circ} \mathrm{C}\right.$ for $15 \mathrm{sec}$ (denaturation); $60^{\circ} \mathrm{C}$ for $1 \mathrm{~min}$ (annealing and extension)]; Step 3,1 cycles of $72^{\circ} \mathrm{C}$ for $1 \mathrm{~min}$. Fluorescence emitted from the FAM dye upon its release from the TaqMan ${ }^{\mathrm{TM}}$ probes was acquired on the FAM/ Sybr channel (470 nm/510 nm filters) of the Rotorgene 3000 at the end of each extension. Samples were tested in duplicate and repeated twice for each cDNA sample synthesized. A standard curve ranging from $10^{7}-10^{2}$ copies of each gene of interest and the control HPRT1 gene was included in each run in duplicate. The external PCR product standards of known number of copies of purified PCR product $/ \mathrm{ml}$ were prepared as previously described (37). Initial processing and analysis of the realtime qPCR data were performed using Rotorgene 6 software (Corbette Research/Qiagen). All qPCR data are represented as a ratio of the number of gene of interest copies to the number of HPRT1 copies multiplied by 1000.

Protein extraction and western blotting. Cell pellets $\left(1-2 \times 10^{7}\right.$ cells) were resuspended in $800 \mu \mathrm{l}$ of buffer [PBS (pH 7.2-7.4) containing $150 \mathrm{mM} \mathrm{NaCl}, 1 \mathrm{mM}$ EDTA, and protease inhibitors $1 \mathrm{mM}$ phenylmethylsulfonyl fluoride (PMSF), $10 \mu \mathrm{M}$ pepstatin A and $10 \mu \mathrm{M}$ leupeptin] and kept on ice. Cells were then lysed by sonication for $3 \times 10 \mathrm{sec}$ on ice. Lysates were separated into soluble and insoluble protein fractions by centrifugation $\left(18,000 \mathrm{~g}\right.$ for $30 \mathrm{~min}$ at $\left.4^{\circ} \mathrm{C}\right)$ and protein concentration determined by Bradford assay (Bio-Rad) as per manufacturer's instructions. Soluble proteins $(50 \mu \mathrm{g})$ were analyzed by SDS-PAGE (8\%) and western blotting as previously described (37). Membranes were probed with either rabbit polyclonal antiDP8 (RP1-DP8; Triple Point Biologics Inc., OR, USA), rabbit polyclonal anti-DP9 (RP1-DP9; Triple Point Biologics Inc.), or rabbit polyclonal anti- $\beta$-actin (ab8227; Abcam), primary antibodies diluted in blocking buffer (RP1-DP8, 1:1000; RP1-DP9, 1:2500; anti- $\beta$-actin, 1:2500). Immunoreactive proteins were visualised using SuperSignal West Pico Chemiluminescent Substrate (ECL reagent) (Thermo Fisher Scientific) and captured using a LAS-4000 imager (Fujifilm Life Science, Tokyo, Japan). All cell lines were harvested on three separate occasions for analysis by western blotting $(n=3)$. Quantification of bands was achieved by densitometry using Multi-Gauge V3.0 software (Fujifilm Life Science). 
Immunostaining and flow cytometry. Surface expression of endogenous DP4 and FAP protein was detected by indirect immunofluorescence staining followed by flow cytometry analysis. DP4 was detected using the anti-human CD26, clone 2A6 (mouse IgG1) (14-0269; eBioscience) and FAP detected using the F19 hybridoma supernatant as previously described (37). Alexa Fluor ${ }^{\circledR} 488$ goat anti-mouse (Molecular Probes ${ }^{\circledR}$, Invitrogen) was used as the secondary antibody. Intracellular protein expression was detected in cells fixed in $4 \%(\mathrm{w} / \mathrm{v})$ paraformaldehyde then permeabilized with $0.1 \%$ (v/v) Triton X-100 in PBS. Labeled cells were analysed on a FACScan (BD Bio Biosciences, San Jose, CA) and analysed using the WinMDI 2.8 (http://facs.scripps.edu) freeware software.

Subcellular fractionation. Cell pellets $\left(>1 \times 10^{7}\right)$ were resuspended in $500 \mu \mathrm{l}$ of homogenization buffer [ $50 \mathrm{mM}$ Tris, $0.32 \mathrm{M}$ sucrose, $5 \mathrm{mM}$ EDTA, $0.05 \%(\mathrm{w} / \mathrm{v}) \mathrm{NaN}_{3}$ ] then incubated for $15 \mathrm{~min}$ on ice with brief vortexing every $5 \mathrm{~min}$. Cells were then homogenized by mechanical disruption with 1-2 strokes of the Ultra-Turrax ${ }^{\circledR}$ T8 (IKA ${ }^{\circledR}$-Werke Staufen, Germany) on speed setting 1-2. The homogenate was centrifuged at 1,500 $\mathrm{g}$ for $10 \mathrm{~min}$ at $4^{\circ} \mathrm{C}$ (Eppendorf 5414C centrifuge; Eppendorf $\mathrm{AG}$, Hamburg, Germany) to remove large debris. Supernatant was separated into membrane and cytosolic extracts by two steps of ultra-centrifugation $\left(100,000 \mathrm{~g}, 30 \mathrm{~min}, 4^{\circ} \mathrm{C}\right)$ in a TL-100 ultracentrifuge (Beckman, USA). After the first round of centrifugation the supernatant was transferred to a clean centrifuge tube and the remaining pellet (representing the membrane protein fraction) was resuspended in $2 \mathrm{ml}$ homogenization buffer for washing. Following the second step of ultra-centrifugation the cytosolic extract was transferred to a clean $1.5 \mathrm{ml}$ tube and placed on ice. Supernatant from the membrane fraction was discarded and the remaining membrane fraction resuspended in $200 \mu \mathrm{l}$ of $0.1 \mathrm{M}$ sodium phosphate buffer $\left(\mathrm{Na}_{3} \mathrm{PO}_{4}, \mathrm{pH} 7.6\right)$ and placed on ice. Samples were immediately used for enzyme assays and determination of protein concentration by Bradford assay (Bio-Rad) as per manufacturer's instructions.

Enzyme assays. DP-like, DP2 and PEP enzymatic activity was assayed colourimetrically using synthetic p-nitroanilide (pNA) containing substrates (Bachem, Switzerland). Observed DP-like activity attributable to DP8, DP9, DP4, FAP and DP2 enzymes was measured using $0.5 \mathrm{mM}$ H-Ala-Pro-pNA in $0.1 \mathrm{M} \mathrm{Na}_{3} \mathrm{PO}_{4}$ pH 7.6. For measurement of DP8, DP9, DP4 and FAP activity the substrate $0.5 \mathrm{mM}$ H-Gly-Pro-pNA in $0.1 \mathrm{M} \mathrm{Na}_{3} \mathrm{PO}_{4} \mathrm{pH} 7.6$ was used; at $\mathrm{pH} 7.6$ the activity of DP2 towards this substrate is likely to be negligible to none (63). DP2 activity was detected using $0.5 \mathrm{mM}$ H-Lys-Ala-pNA in $0.1 \mathrm{M} \mathrm{Na}_{3} \mathrm{PO}_{4} \mathrm{pH}$ 5.5. PEP activity was measured using $0.5 \mathrm{mM}$ Suc-Ala-Pro-pNA in $0.1 \mathrm{M}$ Tris- $\mathrm{HCl} \mathrm{pH}$ 8.0. Enzymatic assays were performed using previously described methods (33). Total activity was calculated using an extinction coefficient of $9.45 \mathrm{mM}^{-1} . \mathrm{cm}^{-1}$ for pNA then corrected for protein concentration. Enzyme activity is expressed as milli-Units (mU) per mg of protein, where, one unit of activity is defined as the amount of enzyme that cleaves one $\mu$ mol of substrate per minute under the given assay conditions.

Statistical analysis. Results are expressed as mean \pm standard error of the mean (SEM). For statistical analysis, the SPSS statistical package (SPSS for Windows, v. 15.0, SPSS, Chicago,
IL, USA) was used. Differences among multiple groups were analysed using one-way or two-way analysis of variance (ANOVA) followed by Bonferroni correction. Differences among two separate groups were analysed using Student's t-test (assumes equal variance) or two sample t-test assuming unequal variance. Where needed, data underwent square-root transformation prior to statistical analysis. A value of $\mathrm{p}<0.05$ was considered significant. For correlation analysis between two samples/factors the Pearson coefficient was used to test for a linear relationship and, in the absence of linearity, a Spearman's correlation test was performed to determine if there was a positive or negative correlation.

\section{Results}

DP8, DP9, DP4, FAP, DP2 and PEP $m R N A$ are differentially expressed in breast and ovarian cancer cell lines. To help characterize the contribution of individual DPs and PEP to the enzyme activities measured in this study we compared the mRNA level expression of all DPs and PEP within each cell line. DP8 mRNA expression was found to be significantly higher $(\mathrm{p}<0.05)$ in all cell lines examined except the MDA-MB453 cell line (large variation in qPCR results) (Fig. 1). Within the breast cancer cell lines, MCF-7 and MDA-MB-231, and ovarian cancer cell line, OVCA-429, the expression of DP8 mRNA was significantly higher than that of all other DPs and PEP(Fig. 1A, B and E). Also within MCF-7 cells the expression of DP2 mRNA was found to be significantly higher than that of FAP (Fig. 1A) while in the MDA-MB-231 cell line the expression of both DP9 and PEP was found to be significantly higher than that of DP4 (no mRNA detected) $(\mathrm{p}=0.022$ and $\mathrm{p}=0.025$, respectively) (Fig. 1B). In OVCA-429 cells the expression of DP9 was found to be significantly higher than that of DP4 and FAP ( $p=0.042$ and $p=0.002$, respectively) (Fig. 1E). In the OVCA-432 cell line DP8 mRNA expression was significantly higher than that of DP9, DP4, DP2 (no mRNA detected) and PEP $(p<0.005)$ but not FAP $(p=0.420)$ (Fig. 1D). In the ovarian cancer cell line, SKOV3, DP8 mRNA was significantly higher than DP9, FAP, DP2 and PEP $(\mathrm{p}<0.005)$ but not DP4 $(\mathrm{p}=1.000)$ (Fig. 1D). The expression of DP4 mRNA in SKOV3 cells was significantly higher than the levels of FAP and DP2 (no mRNA detected) ( $\mathrm{p}=0.006$ and $\mathrm{p}=0.01$, respectively) (Fig. 1D). In the non-cancer derived $293 \mathrm{~T}$ cells, DP8 mRNA expression was significantly higher than that of DP4, FAP, DP2 and PEP $(\mathrm{p}<0.005)$ but not DP9 ( $\mathrm{p}=0.113)$ (Fig. 1G). HeLa cells are a commonly used cervical cancer derived cell line that were included in this study as a contrast to the breast and ovarian cancer cell lines. In HeLa cells DP8 mRNA expression was significantly higher than that of DP9, DP4, FAP, PEP and DP2 $(\mathrm{p}=1.000)$ (Fig. 1H). DP2 mRNA expression in HeLa cells was significantly higher than that of DP4 (no mRNA detected) (Fig. 1H). Both DP4 and DP2 mRNA were completely absent in three cell lines; however, dual negative expression of both was only observed in the breast cancer cell line, MDA-MB-453 (Fig. 1C).

No correlation between $m R N A$ level expression of any DPs or $P E P$. Correlation testing was performed to examine whether any relationship amongst the expression of DPs and PEP existed at the mRNA level. A moderate positive non-linear correla- 


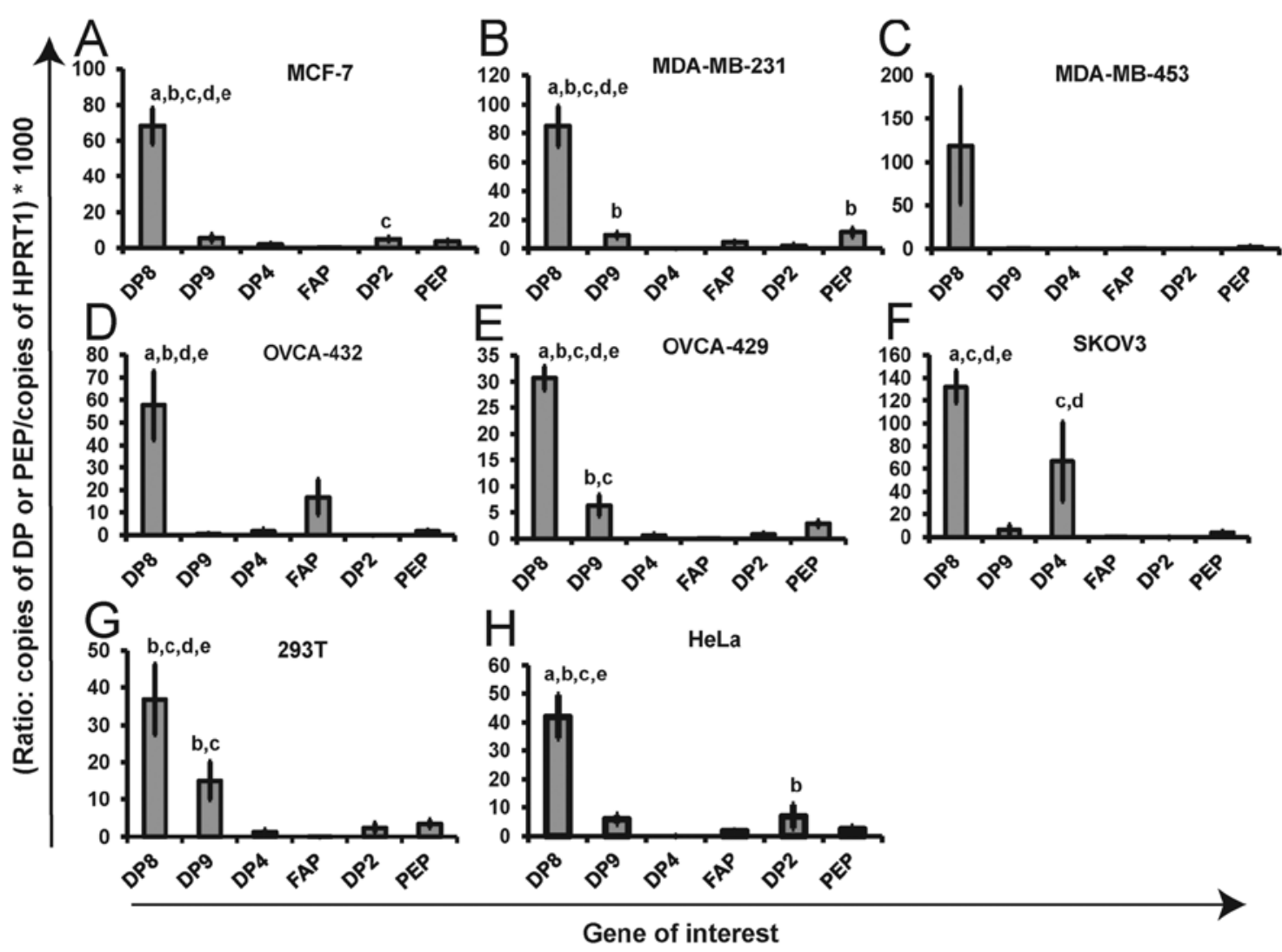

Figure 1. DP and PEP mRNA expression levels within individual cell lines. DP8, DP9, DP4, FAP, DP2 and PEP mRNA expression is displayed for three breast cancer [MCF-7 (A), MDA-MB-231 (B), MDA-MB-453 (C)], three ovarian cancer, [OVCA-432 (D), OVCA-429 (E), SKOV3 (F)] and two alternate [293T (G) and $\mathrm{HeLa}(\mathrm{H})]$ cell lines. Shown on each graph is the ratio of the copies of each gene of interest/copies of HPRT1 (housekeeping gene) multiplied by 1000 for ease of visual comparison. The expression of each gene was determined in duplicate for two sets of cDNA synthesized from each cell line (four replicates in total). Values displayed as mean \pm SEM $(n=4)$. Statistically higher expression $(\mathrm{p}<0.05)$ of a gene compared to other genes within a given cell line is indicated by $(a=D P 9 ; b=D P 4 ;$ $\mathrm{c}=\mathrm{FAP} ; \mathrm{d}=\mathrm{DP} 2, \mathrm{e}=\mathrm{PEP})$. DP8 was expressed at significantly higher levels in all cell lines $(\mathrm{p}<0.05)$. Statistical significance was determined by two-way ANOVA using Bonferonni Correction.

tion was observed between DP9 and PEP mRNA expression however the finding was non-significant $(r=0.643, \mathrm{p}=0.083$, Spearman's correlation test). Apart from this, no linear relationship or non-linear correlation was observed between the mRNA level expression of the DPs and PEP (data not shown).

Ubiquitous DP8 and DP9 protein expression across all cell lines. Endogenous DP8 and DP9 protein levels were assessed in the breast and ovarian cancer cell lines. In agreement with mRNA expression data, both DP8 and DP9 were found to be ubiquitously but differentially expressed across all cell lines at the protein level (Fig. 2A and C). Three prominent DP8 immunoreactive bands of mobility around $\sim 100 \mathrm{kDa}, 135 \mathrm{kDa}$ and $180 \mathrm{kDa}$ were detected with the anti-DP8 (RP1-DP8) antibody. Smaller molecular mass bands were also detected between the $53 \mathrm{kDa}$ and $99 \mathrm{kDa}$ size markers (Fig. 2A). Two prominent DP9 immunoreactive bands of monomeric molecular mass $\sim 100 \mathrm{kDa}$ and a smaller molecular mass between the $53 \mathrm{kDa}$ and $99 \mathrm{kDa}$ size markers were detected in all cell lines (Fig. 2C). Quantitative densitometry analysis of the combined $100 \mathrm{kDa}$, $135 \mathrm{kDa}$ and $180 \mathrm{kDa}$ bands of DP8 (Fig. 2B), revealed a nonsignificant decrease in DP8 protein levels in all three breast cancer cell lines compared to the three ovarian cancer cell lines $(p=0.057$; two sample t-test). A slight decrease in expression was also observed in all three breast cancer cell lines compared to the 293T and HeLa cells however this was also not significant. Quantitative densitometry analysis of the $\sim 100 \mathrm{kDa}$ monomeric band of DP9 protein revealed no significant differences in DP9 protein levels in MCF-7, OVCA-432, OVCA-429 and SKOV3 cell lines (Fig. 2D). The highest level of DP9 protein was detected in the two estrogen receptor negative cell lines, MDA-MB-231 and MDA-MB-453 (Fig. 2D). Interestingly, these were the two breast cancer cell lines found to be negative for DP4 mRNA (Fig. 2B and C).

DP4 and FAP are differentially expressed on the surface of cell lines. DP4 protein was detected on the surface of all three ovarian cancer cell lines, the MCF-7 breast cancer cell line and 293T cells (Fig. 3A). Corresponding with high levels of mRNA, the highest level of surface DP4 protein was detected on SKOV3 and OVCA-432 cells (Fig. 3A). No DP4 protein was detected on the surface of the DP4 mRNA negative cell lines, MDA-MB-231, MDA-MB-453 and HeLa (Fig. 3A). Surface staining revealed the expression of FAP as a weak antigen on MDA-MB-231 and HeLa cells (Fig. 3B). Little to no FAP protein was detected in the other cell lines (Fig. 3B) including OVCA-432 cells in which the highest levels of FAP mRNA were detected.

Intracellular expression of FAP protein. The weak surface antigen expression of FAP on MDA-MB-231 and HeLa cell 



Figure 2. DP8 and DP9 protein expression in breast and ovarian cancer cell lines. Western blotting of (A) DP8 and $\beta$-actin (control) and (C) DP9 and $\beta$-actin (control) protein expression in lysates of breast cancer (MCF-7, MDA-MB-231, MDA-MB-453), ovarian cancer (OVCA-432, OVCA-429, SKOV-3) and two alternate (293T and HeLa) cell lines. Protein samples $(50 \mu \mathrm{g})$ were boiled in the presence of 3.33\% (v/v) $\beta$-mercaptoethanol and loaded on an $8 \%$ SDS-PAGE, and immunoblot analysis was performed. (B) Densitometry of DP8 (100, 135 and $180 \mathrm{kDa}$ bands in A) expression relative to $\beta$-actin. (D) Densitometry analysis of DP9 monomer (indicated on C) protein expression relative to $\beta$-actin. Values are expressed as the mean $\pm \mathrm{SEM}(\mathrm{n}=3)$. Western blot images are representative from three independent experiments. Full length DP8 and DP9 forms of $\sim 100 \mathrm{kDa}$ are indicated by an arrow.

lines was indicative of the FAP protein being expressed as an intracellular antigen. Intracellular expression of FAP in MDA-MB-231 and HeLa cells was confirmed following cell permeabilization (Fig. 3C).

DP9 and DP4 protein levels correlate. To investigate whether there was any potential relationships/co-regulation of DP8, DP9, DP4 and FAP at the protein level, correlation analysis was performed. No correlation was observed between DP8 protein and the DP9, DP4 or FAP proteins (data not shown). However, a strong negative, non-linear, correlation was observed between DP9 and DP4 protein level expression $(\mathrm{r}=-0.810, \mathrm{p}=0.015$, Spearman's correlation test; Fig. 4A). Conversely, a positive, non-linear, correlation was observed between DP9 protein and surface FAP protein $(r=0.798, p=0.18$, Spearman's correlation test; Fig. 4B). A moderate negative correlation was observed between DP4 and FAP protein expression but this finding was non-significant $(r=0.667, p=0.071$, Spearman's correlation test; Fig. 4C).
Correlation analysis of DP8, DP9, DP4 and FAP protein expression with DPs and PEP $m R N A$ expression. It may be possible that protein levels of the DPs may affect their own gene expression via regulatory feedback loops or, may affect the gene expression of other DPs and PEP. To address this, the levels of DP8, DP9, DP4 and FAP protein expression were examined across all cell lines in comparison with mRNA levels of the DPs and PEP. Although not directly related, due to overlap in enzymatic activity and specificity, DP2 and PEP were included in this analysis. A strong positive linear correlation was observed between the level of DP4 protein and DP4 mRNA ( $r=0.998$, $\mathrm{p}=0.000$, Pearson coefficient; data not shown). DP4 was the only DP displaying a correlation between the level of DP mRNA expression and DP protein expression. No correlation was found between the expression of DP8 protein and mRNA expression of any of the DPs or PEP (data not shown). Interestingly, a strong negative correlation was observed between the level of DP9 protein expression and DP4 mRNA expression ( $\mathrm{r}=-0.903$, $\mathrm{p}=0.002$, Spearman's correlation test; data not shown). However, 

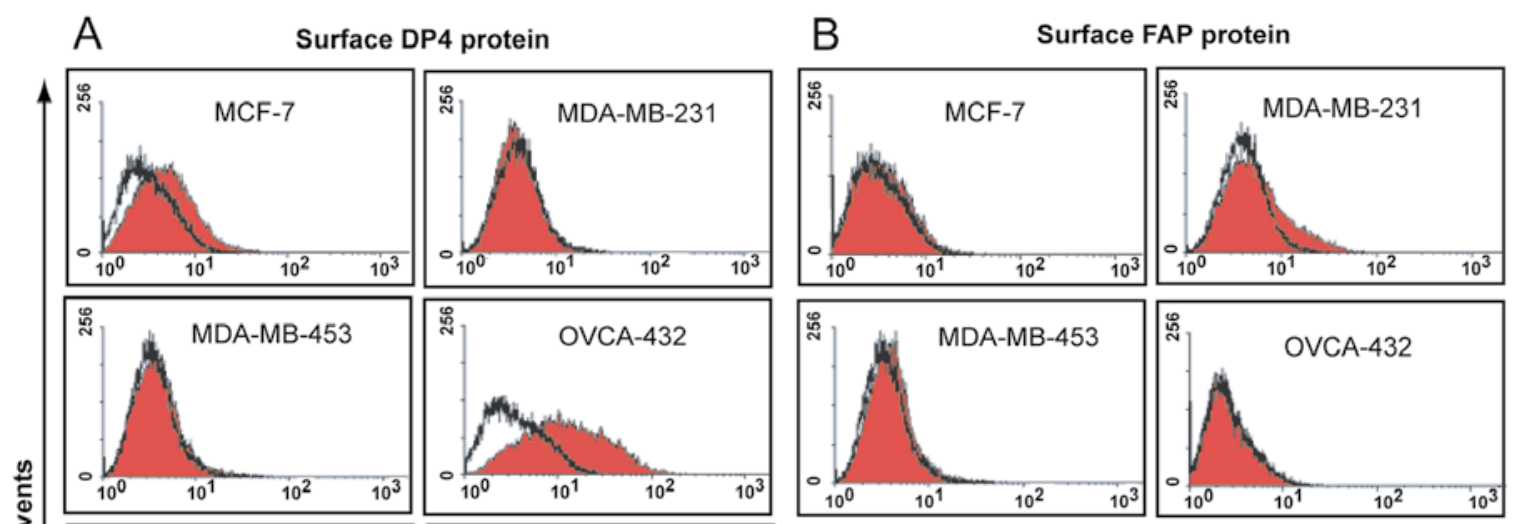

岁


Fluorescence Intensity

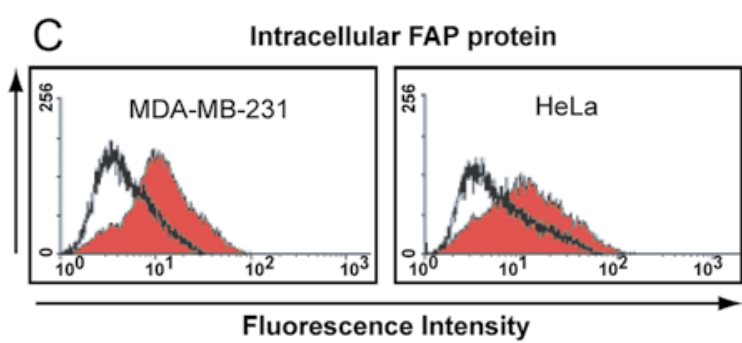

Figure 3. DP4 and FAP protein expression in cancer cell lines. Expression of DP4 (A) and FAP (B) protein was determined on the surface of MCF-7, MDA-MB-231, MDA-MB-453, OVCA-432, OVCA-429, SKOV3, 293T and HeLa cells. DP4 protein expression was determined by flow cytometry analysis using affinity purified mouse anti-human CD26 antibody. FAP protein expression on surface of cells was determined by flow cytometry using F19 hybridoma supernatant. Alexa Fluor 488 conjugated goat anti-mouse was used as the secondary antibody. Intracellular expression of FAP was confirmed using FACS of cells permeabilized with $0.1 \%$ Triton X-100 before staining (C). Histograms are representative from three independent experiments. Non-filled histogram plots of IgG1 negative controls are overlayed.

no correlation was observed between DP4 protein and DP9 mRNA (data not shown), suggesting a non-reciprocal relationship between DP4 expression and DP9 protein levels. A moderate negative correlation was observed between the level of expressed FAP protein and DP4 mRNA expression $(\mathrm{r}=-0.708$, $\mathrm{p}=0.050$, Spearman's correlation test; data not shown) but no correlation was observed between the level of DP4 protein and FAP mRNA (data not shown).

Enzyme activity of DPs, DP2 and PEP in membrane and soluble fractions of breast and ovarian cancer cells. To characterize the level of DP-like, DP2 and PEP activity within each cell line statistical analysis was performed to examine the difference in activity between fractions (membrane and soluble) for each substrate within each cell line and the difference in activity between substrates within each fraction within each cell line (Fig. 5).

Comparison of activities between substrates within each fraction revealed no significant difference between activities in membrane fractions of MCF-7, MDA-MB-231 and MDA-MB-453 cells and in soluble fractions of MCF-7 and MDA-MB-453 cells. In the soluble fraction of MDA-MB-231 cells the level of DP-like and PEP activities were significantly higher than the level of DP2 like activity $(\mathrm{p}<0.01)$ (Fig. 5B). In the DP4 positive ovarian cancer cell lines, OVCA-432 and SKOV3, the level of DP-like activity against both H-AlaPro-pNA and H-Gly-Pro-pNA, and the level of DP2 like activity against H-Lys-Ala-pNA (OVCA-432 cells only), was significantly higher in the membrane fraction compared to the soluble $(\mathrm{p}<0.05)$ (Fig. 5D and F). In OVCA-429 cells the level of PEP like activity against Suc-Ala-Pro-pNA was significantly higher in the soluble fraction compared to membrane $(p<0.01)$ (Fig. 5E). Comparison of activities between substrates within fractions revealed that in membrane fractions of OVCA-432 and SKOV3 cells the level of DP-like activity was significantly higher than the level of DP2 and PEP like activity $(\mathrm{p}<0.01)$ (Fig. 5D and F) and, in OVCA-429 membrane fractions the level of DP-like activity against H-Ala-Pro-pNA was significantly 

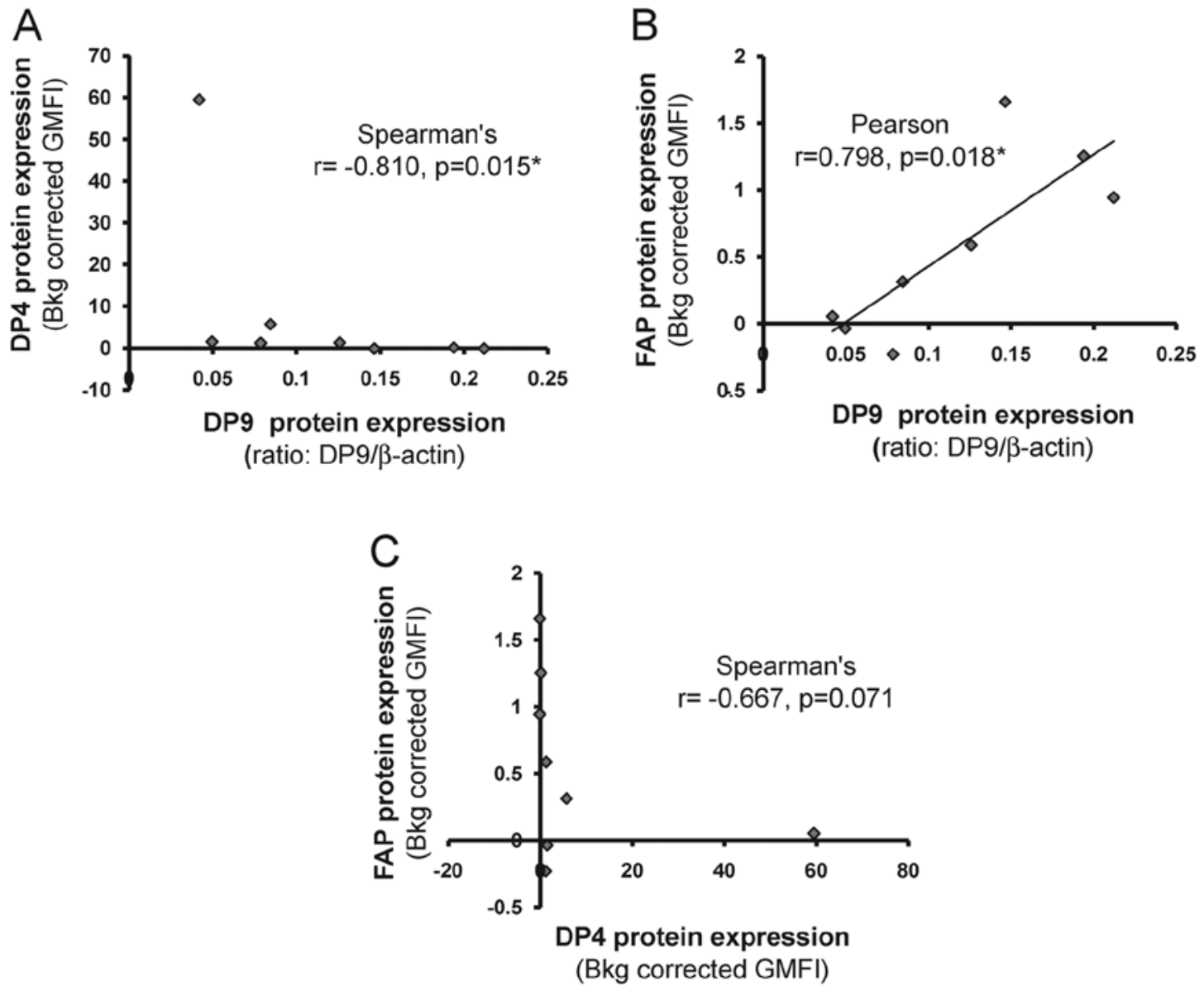

Figure 4. Correlation between DP9, DP4 and FAP proteins in breast and ovarian cancer cell lines. The level of DP4 (A) or FAP (B and C) protein (y-axis) expressed as the geometric mean fluorescence intensity (GMFI) of histograms from flow cytometry analysis (Fig. 3A and B) was plotted against the level of DP9 (A and B) protein (x-axis), expressed as the ratio of DP9 protein/ $\beta$-actin control, as determined by western blot analysis (Fig. 2C and D) or FAP was also plotted against the level of DP4 (C) protein (x-axis) determined from flow cytometry analysis as described. Fit of linearity was measured by Pearsons coefficient while non-linear correlation was calculated using two-tailed Spearman's correlation test in SPSS v15.0 software. GMFI, geometric mean fluorescence intensity; Bkg, background.

higher than the level of PEP like activity ( $\mathrm{p}=0.01)$ (Fig. 5E). In soluble fractions of OVCA-432 and OVCA-429 cells the level of PEP like activity and the level of DP-like activity against H-Ala-Pro-pNA (OVCA-432 cells only), was significantly higher than the level of DP2 like activity (Fig. 5D and E). No significant difference was observed between substrates in the soluble fraction of SKOV3 cells.

In both 293T and HeLa cells the level of membrane DP2 like activity against H-Lys-Ala-pNA was significantly higher than soluble activity $(\mathrm{p}<0.05)$ and, in 293T cells the level of soluble PEP like activity against Suc-Ala-Pro-pNA was significantly higher than membrane activity $(\mathrm{p}=0.01)$ (Fig. 5G and F). In soluble fractions of 293T and HeLa cells the level of PEP like activity was significantly higher than the level of DP-like activity against H-Gly-Pro-pNA and H-Ala-Pro-pNA (293T cells only) and, in HeLa cells only, the level of DP2 like activity (Fig. 5F and $\mathrm{G}$ ). In addition the level of soluble DP-like activity against H-Ala-Pro-pNA was significantly higher than the level of soluble DP2 activity in 293T cells (Fig. 5G). No significant difference was observed between substrates in the membrane fraction of 293T and HeLa cells.
Correlation analysis between DP8, DP9, DP4 and FAP protein with observed DP-like, DP2 and PEP like enzyme activities. To further characterize the enzymes responsible for the observed activities statistical analysis was performed to test for correlation between protein levels of DP8, DP9, DP4 and FAP and the level of DP-like activity in membrane and soluble fractions of each cell line. Correlation tests were also performed to determine whether there was any possible relationship (e.g. co-regulation of enzymes) between the level of DP8, DP9, DP4 and FAP protein and observed level of activities against the DP2- and PEP-like substrates, H-Lys-Ala-pNA and Suc-AlaPro-pNA. No correlation between DP8 protein and soluble DP-like, DP2- and PEP-like activities or between the level of DP9 protein and soluble DP-like and PEP-like activity was observed (data not shown). A strong positive linear relationship was observed between the level of expressed DP4 protein and the level of membrane activity against the DP-like substrates, H-Ala-Pro-pNA ( $\mathrm{r}=0.993, \mathrm{p}=0.000$, Pearson coefficient) and H-Gly-Pro-pNA ( $r=0.987, p=0.000$, Pearson coefficient; data not shown). A moderate negative, but not significant, non-linear correlation was observed between the level of FAP protein and 


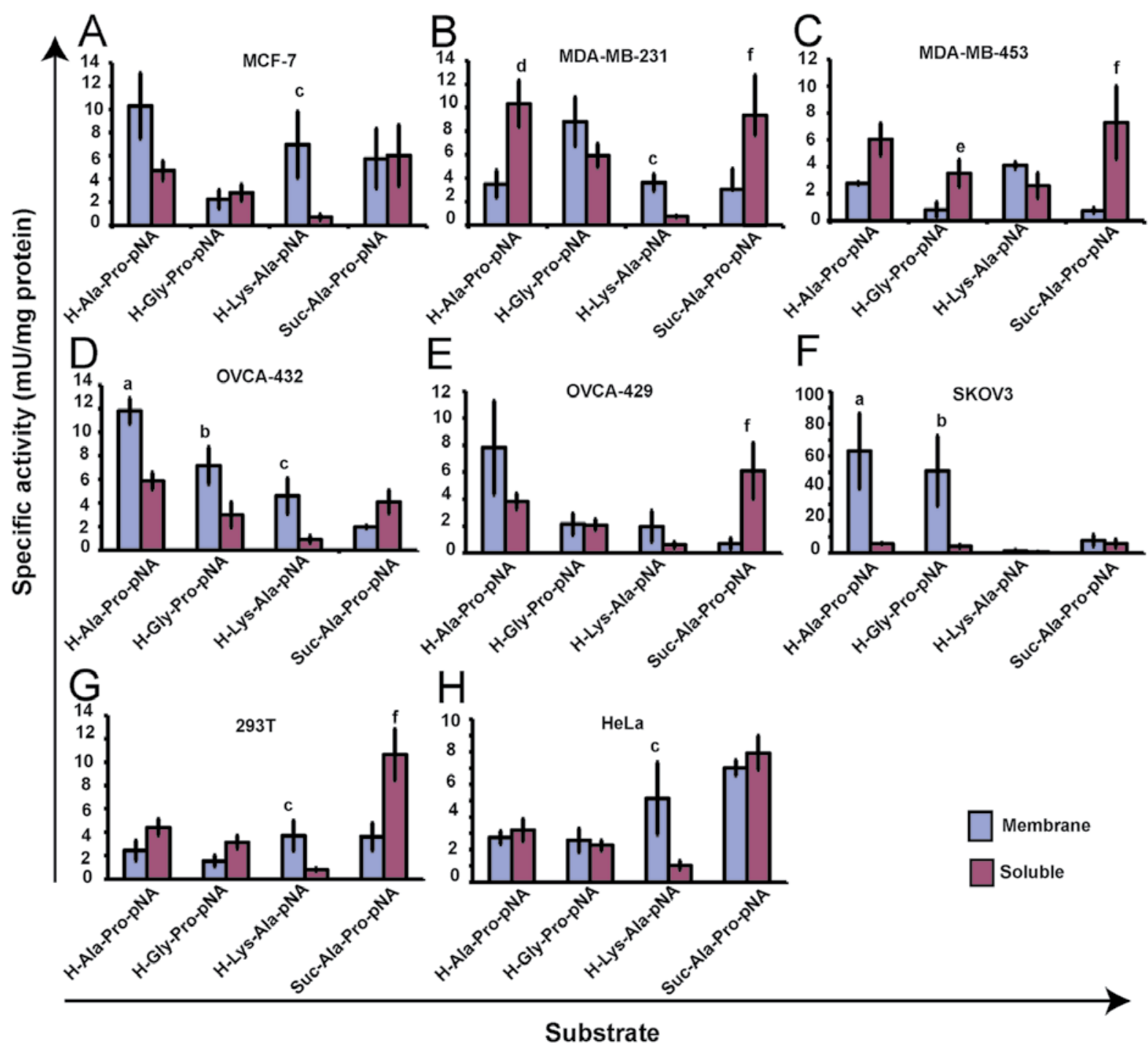

Figure 5. DP-like, DP2 and PEP enzyme activity within each cell line. Enzyme activity against the DP-like synthetic substrates H-Ala-Pro-pNA and H-GlyPro-pNA, the DP2 synthetic substrate, H-Lys-Ala-pNA and the PEP synthetic substrate, Suc-Ala-Pro-pNA is displayed for three breast cancer cell lines, MCF-7 (A), MDA-MB-231 (B), MDA-MB-453 (C), three ovarian cancer cell lines, OVCA-432 (D), OVCA-429 (E), SKOV3 (F) and two alternate cell lines, 293T (G) and $\mathrm{HeLa}(\mathrm{H})$. Values are expressed as the mean \pm SEM $(\mathrm{n}=3)$. Statistical significance $(\mathrm{p}<0.05)$ was determined by one-way and two-way ANOVA using Bonferonni Correction. Significance was tested between fractions for each substrate within each cell line and between substrates within each fraction within each cell line. Significance is represented on the Figure as follows: (a) indicates higher activity against H-Ala-Pro-pNA in membrane fraction compared to soluble fraction; (b) indicates higher activity against H-Gly-Pro-pNA in membrane fraction compared to soluble fraction; (c) indicates higher activity against H-Lys-Ala-pNA in membrane fraction compared to soluble fraction; (d) indicates higher activity against H-Ala-Pro-pNA in soluble fraction compared to membrane fraction; (e) indicates higher activity against H-Gly-Pro-pNA in soluble fraction compared to membrane fraction; (f) indicates higher activity against Suc-Ala-Pro-pNA in soluble fraction compared to membrane fraction.

membrane activity against H-Ala-Pro-pNA (r=-0.643, p=0.086, Spearman's correlation test; data not shown).

Correlation analysis between DP2 and PEP $m R N A$ with observed DP2- and PEP-like enzyme activities. Correlation tests were performed to test whether there was any relationship between the level of DP2 and PEP mRNA expression and the level of activities against the H-Lys-Ala-pNA and Suc-Ala-Pro-pNA substrates. No correlation was observed between the level of DP2 mRNA and the level of soluble activity against H-Lys-Ala-pNA (Fig. 6A). In contrast, a moderate positive, but non-significant, linear relationship was observed between the level of DP2 mRNA and membrane activity against the substrate H-Lys-Ala-pNA ( $\mathrm{r}=0.636$, $\mathrm{p}=0.90$, Pearson coefficient; Fig. 6B).

\section{Discussion}

To date no one has investigated DP8 and DP9 expression in human breast and ovarian cancer or their expression in context with that of DP4 and FAP in cancer. This study demonstrates the ubiquitous but differential expression of DP8 and DP9 protein in breast and ovarian cancer cell lines, which may implicate each of these proteases in cancer pathogenesis. The lack of correla- 

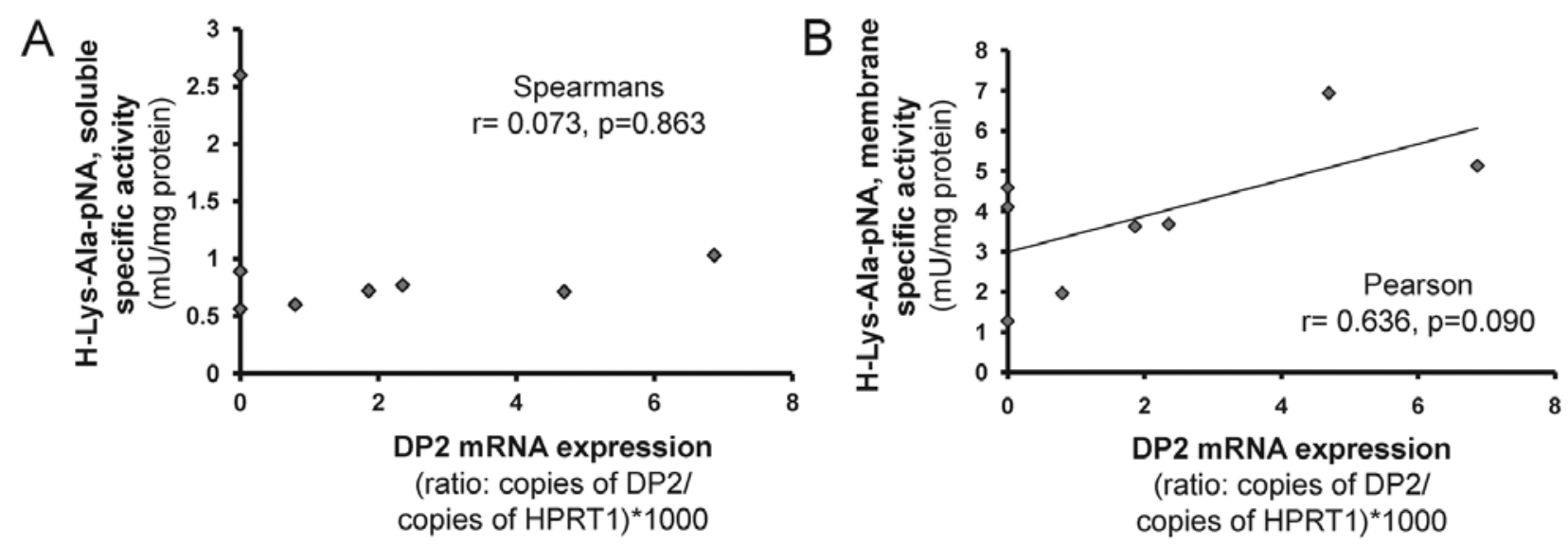

Figure 6. Correlation between DP2 mRNA level expression and H-Lys-Ala-pNA cleavage. The level of DP2-like activity (y-axis) against the synthetic substrate H-Lys-Ala-pNA, in the soluble (A) and membrane (B) fractions of each cell line was plotted against the level of DP2 mRNA expression (x-axis), expressed as the ratio of copies of DP2/copies of HPRT1 multiplied by 1000, from each cell line. Fit of linearity was measured by Pearsons coefficient while non-linear correlation was calculated using two-tailed Spearman's correlation test in SPSS v15.0 software.

tion between transcript and protein levels for both DP8 and DP9 suggests that post-transcriptional regulation plays an important role in regulating DP8 and DP9 protein levels. DP8 protein levels were lower in the breast cancer cell lines compared to the ovarian cancer, 293T and HeLa cells, suggesting that a breast cancer specific factor is contributing to its aberrant regulation, leading to increased protein turnover or decreased protein synthesis. For the first time we have identified a negative nonreciprocal relationship between the expression of DP9 protein and DP4 mRNA and protein expression, strongly suggesting that the post-transcriptional regulation of DP9 is influenced/ under the control of a negative DP4 regulator. The relationship between DP9 and DP4 is an important avenue for further studies due to the conflicting roles of DP4 in cancer and the potential involvement of DP9 in these cancers.

Using DP4, DP2 and DP8/DP9 selective inhibitors, DP8/ DP9-like activity has been isolated in human leukocytes (51) non-malignant human brain tissue (40), human meningiomas (39) and bovine and rat testes (35). DP8 and DP9 mRNA expression has been measured by qPCR in non-malignant human brain tissue (40) and human meningiomas (39). In human meningiomas, DP8 and DP9 protein have been detected by the use of specific DP8/DP9 antibodies for immunohistochemistry (39). To date no one has examined the levels of DP8 and DP9 in breast and ovarian cancer cell lines or patient samples. In patient samples of human meningiomas, a non-glial brain tumor, DP8 and DP9 mRNA and proteins are more abundantly expressed than DP4 and FAP (39). In these samples, the expression of DP4 mRNA was found to positively correlate with the expression of FAP mRNA (39). However, quantitative analysis of DP8/DP9 protein levels in context with DP4 and FAP was not determined in these samples (39). Interestingly, we identified a moderate negative, non-reciprocal correlation between the level of expressed FAP protein and DP4 mRNA in breast and ovarian cancer cell lines but found no correlation between FAP and DP4 mRNA. Both DP4 and FAP are located adjacent to each other on the long arm of chromosome 2 (52) and their co-transcriptional regulation has been previously suggested (53). The identification of a negative correlation between FAP protein and DP4 mRNA and protein may suggest that, similar to DP9, DP4-dependent post-transcriptional regulation of FAP is occurring in breast and ovarian cancer cell lines. A significant increase in DP8 mRNA has been observed in human CLL compared to normal tonsil B-lymphocytes however, this finding did not correlate with an increase in DP8 protein (37). In CLL, the expression of DP9 mRNA was also higher in normal tonsil B-lymphocytes compared to CLL (37). In tissues from testicular cancer patients, a significant increase in DP9 mRNA was observed compared to controls, however, the level of DP9 protein was not determined in this study (38). All cell lines used in our study were originally of epithelial origin (Table I). Thus, the high level of ubiquitously expressed DP8 mRNA suggests the importance of this enzyme in epithelial cells. In each of these cell lines ubiquitous but differential expression of DP8 and DP9 mRNA and protein was detected but no correlation was observed between the levels of mRNA and protein. This highlights the importance in following gene expression measurements with protein-based investigations.

While low, but ubiquitous expression of FAP mRNA was detected in all cell lines, its translated protein product was only detected in MDA-MB-231 and HeLa cells. The identification of FAP as an intracellular antigen suggests that FAP may be stored in intracellular compartments of MDA-MB-231 and HeLa cells where it remains until external stimuli results in translocation, and presentation of FAP on the surface of these cells. Expression of DP4 protein was strongly correlated, in a linear manner, with its mRNA expression. In contrast, the level of ubiquitously expressed DP8 and DP9 mRNA did not correlate with their level of ubiquitously expressed protein, suggesting that posttranscriptional regulation plays an important role in controlling translation of these proteins in breast and ovarian cancer and/or that post-translational turnover is high.

The size of immunoreactive DP8 and DP9 protein bands detected by western blotting are consistent with previous studies $(33,36,54)$. The detection of a smaller molecular mass immunoreactive band between $53 \mathrm{kDa}$ and $99 \mathrm{kDa}$ for both 
DP8 and DP9 may be the result of specific degradation products, suggesting high lability of DP8 and DP9, or may be an alternative translation product/splice variant. High lability has also been observed for recombinant DP8/DP9 proteins $(6,55)$. Interestingly, for the first time a strong negative non-reciprocal relationship was identified between DP9 and DP4. It is likely that this relationship is cell line and/or tissue dependent in the context of pathogenic conditions.

The positive linear relationship observed between expression of DP9 and FAP proteins is most likely due to the post-transcriptional level effects of DP4 expression on both these proteins and not an independent relationship between DP9 and FAP. Increase in DP4 mRNA and protein decreases the level of DP9 protein but not mRNA and correlates with the absence of FAP protein expression but not mRNA. No reciprocal relationship was observed between DP9 mRNA or FAP mRNA and DP4 protein suggesting that DP4 is the key player in this negative relationship. It can be speculated that despite the primarily cytoplasmic localization of DP9, in the event of decreased or lost DP4 expression, DP9 protein levels may increase and eventuate in its translocation to the plasma membrane were it compensates for some of the loss of DP4 activity. Evidence supporting the presence of DP9 and/or DP8 on the surface of DP4 negative lymphoid cells, including flow cytometry detection of DP9 protein on the surface of cells, has recently been presented (56). Furthermore, it has been suggested that DP9 may play a compensatory role in cell growth regulation in $\mathrm{DP}^{-/-}$mice (57).

Due to the absence of FAP protein on the surface of SKOV3 cells and the complete absence of DP2, the significantly higher level of DP-like activity in the membrane fraction of SKOV3 cells, compared to all other cell lines, can be attributed to DP4. In this study we detected the highest level of expressed DP4 protein on the surface of SKOV3 cells. This is in contrast to other studies were SKOV3 cells were found to have low DP4 expression and were hence used for gain-of-function studies involving overexpression of DP4 $(23,58)$. Previously, MDA-MB-231 cells were found to be FAP mRNA negative (30) as determined by northern blot analysis. Heterologous overexpression of FAP in MDA-MB-231 has been shown to provide a gain-of-function leading to more rapid tumor growth compared to controls in mouse models $(31,59)$. The difference in expression of DP4 and FAP in the present study suggests that morphological changes have likely occurred due to differences in routine cell culture and handling between international research groups and the importance of re-phenotyping cell lines before beginning these types of over and under expression studies.

In MDA-MB-231 cells, the significant increase in activity against $\mathrm{H}$-Ala-Pro-pNA, but not H-Gly-Pro-pNA is likely due to the intracellular expression of FAP which kinetically favours the hydrolysis of H-Ala-Pro-substrates over H-Gly-Pro-substrates $(8,60)$. With the exception of MDA-MB-231 cells, the level of soluble DP-like activity was fairly constant across all cell lines (no significant differences). Apart from the contribution of intracellular FAP in MDA-MB-231 cells, this study suggest that DP8 and/or DP9 are the major enzymes responsible for the observed DP-like activity in soluble fractions of all cell lines with the contribution of DP2 to these activities being negligible. This is supported by the detection of little to no enzyme activity against the DP2 substrate of H-Lys-Ala-pNA in soluble fractions of cell lines and the complete absence of DP2 at the mRNA level in MDA-MB-453, OVCA-432 and SKOV3 cells, all of which were positive for DP8 and DP9 at the mRNA and protein level.

Although DP2 is a soluble enzyme, it is primarily localized to vesicular structures (61) making it highly probable that its activity will be observed in membrane fractions of the cell lines isolated in this study. Indeed, as displayed in Fig. 5, a higher level of DP2 activity was observed in the membrane fractions of cell lines. In addition, a moderately positive but non-significant correlation was detected between DP2 mRNA and membrane H-Lys-Ala-pNA activity. However, membrane activity against H-Lys-Ala-pNA was detected in all cell lines, including in the three cell lines negative for DP2 mRNA, MDA-MB-453, OVCA-432 and SKOV3 cells. Therefore, we cannot exclude the likelihood of another enzyme being responsible for some of the observed DP2-like activity in the cell lines that are DP2 negative or positive at the mRNA level. Likewise, in soluble fractions the level of activity against H-Lys-Ala-pNA was fairly constant and may be due to the expression of some DP2 protein, in the DP2 positive cell lines, and another enzyme. Of most interest was the identification of a significantly positive correlation between the level of DP9 protein and soluble activity against H-Lys-Ala-pNA. Purified recombinant DP9 retains a low level of residual activity against H-Ala-Pro-pNA at acidic pH 5.5 (62) thus we can speculate that DP9 may be responsible for some of the soluble activity against H-Lys-Ala-pNA observed in the present study. Although DP4 is capable of cleaving H-Lys-Ala-pNA, its activity at acidic $\mathrm{pH} 5.5$ is negligible (63) thus it is not likely to be the enzyme responsible for the observed DP2-like activity. In addition, significantly higher levels of activity were detected in the membrane fraction compared to soluble fraction of the DP4 and DP2 negative MDA-MB-453 cells. These findings suggest that an alternate membrane-associated enzyme, or enzymes, is responsible for hydrolysis of H-Lys-Ala-pNA at an acidic $\mathrm{pH}$. This is further supported by the detection of residual activity against H-Lys-Ala-pNA in intact cells following treatment with selective DP2 inhibitors $(64,65)$. As a number of aminopeptidases are capable of cleaving N-terminal Lys and Ala residues (66-69) it is reasonable to suggest that one or more aminopeptidases may be responsible for the cleavage of Lys, then Ala, from the synthetic substrate and thus release of pNA for colorimetric detection in the DP2 enzyme assay.

The higher level of endopeptidase activity against Suc-AlaPro-pNA in soluble fractions compared to membrane fractions is consistent with the cytosolic localization of PEP. Forms of membrane bound PEP have been identified (70) and may be responsible for some of the detected membrane endopeptidase activity against Suc-Ala-Pro-pNA. Unique to the DP4-like gene family, FAP also has endopeptidase activity (60), displaying a strong specificity for $\mathrm{NH}_{2}$-Gly-Pro-substrates (71), poorly cleaving synthetic Suc-Ala-Pro containing substrates (8). Thus, its contribution to the activity against Suc-Ala-Pro-pNA in FAP positive MDA-MB-231 and HeLa is likely to be minimal, if any.

Recent data suggest that high levels of endogenous DP4, DP8 and DP9 can provide a survival mechanism for ESFT, protecting ESFT cells from endogenous NPY-induced cell death (16) while heterologous overexpression of DP8 and DP9 has been shown to enhance staurosporine-induced apoptosis and spontaneous apoptosis in the case of DP9 $(17,36)$. These differences highlight 
the importance of investigating endogenous expression of DPs in the context of differing pathological settings. Furthermore, it suggests that the roles of DP8 and DP9 may be tumor specific. As we have found in the present study, the expression of DP4 in relation to DP9 is likely to play an important role in breast and ovarian cancer pathogenesis. Lu et al investigated the roles of DPs in ESFT, individual siRNA knockdown of DP4, DP8, DP9 and FAP was performed in human ESFT cell lines, however no increase in DP9 mRNA levels was detected following siRNA decrease in DP4 mRNA (16). Unfortunately, the Lu et al study did not measure protein level expression. In all cell lines analyzed in our study, we observed no correlation between the endogenous expression of DP8 and DP9 mRNA and protein. This is consistent with the Yao et al observation of no change in DP8 protein expression following heterologous overexpression of DP9 in HEK293T and HepG2 cells (36).

Yao et al showed that DP9 overexpression inactivated phosphoinositide 3-kinase (PI3K)/Akt signaling in an epidermal growth factor (EGF)-dependent manner, attenuating cell proliferation and enhancing apoptosis (36). Akt is a key activator of cell growth and survival mechanisms (72). Dysregulation of the PI3K/Akt pathway resulting in enhanced Akt signaling is a common feature of many cancers, including breast and ovarian cancer $(73,74)$, that helps drive tumorigenesis (72). Thus drugs inhibiting the PI3K/Akt molecular pathway are attractive for the therapeutic treatment of breast and ovarian cancer $(72,73,75)$. Aberrant expression of the EGF receptor (EGFR) is also observed on the surface of numerous cancers; thus, a complex interplay between levels of EGFR, DP9, and members of the PI3K/Akt pathway are likely to contribute to context specific roles of DP9 in cancer. Inhibition of the Akt pathway may be a potential mechanism by which overexpression of DP9 enhances apoptosis in HepG2 and HEK293T cell lines and implicates a potential therapeutic role for DP9 in breast and ovarian carcinoma.

Breast cancer is a largely hormone-dependent cancer with the status of steroid hormones, including estrogen, progesterone and androgen, and the expression of human epidermal growth factor receptor 2 (HER2) playing a prominent role in the development and progression of tumors (76-79). MCF-7 cells used in this study are one of the most widely utilized cell models for estrogen receptor (ERc) positive breast cancer (60). In contrast, the other two breast cancer cell lines, MDA-MB-231 and MDA-MB-453, are ERc negative. MDA-MB-231 are known to be highly invasive and are positive for EGFR expression while MDA-MB-453 cells are weakly invasive, and lack EGFR expression (42). All three ovarian cancer cell lines, OVCA-429, OVCA-432 and SKOV3 are ERc ${ }^{+}$(44); however, despite having a functional estrogen receptor SKOV3 cells are unresponsive to estrogen or anti-estrogen treatment (47). SKOV3 cells express high levels (over-express) HER2 while both OVCA-432 and OVCA-429 cells express lower levels of HER2 in relation to SKOV3 cells (46). Interestingly, the absence of DP4 expression in breast cancer cell lines, MDA-MB-231, MDA-MB-453 and HeLa cells coincides with the reported ERc negative status of these lines. An increase in DP4 expression upon increasing ERc positive nature of ovarian cancer patient samples has been previously reported; however, no correlation was found between DP4 protein and steroid hormone receptor expression or severity of disease in patients (80). The findings in our current study suggest that this should be revisited and investigated in the context of DP9 and DP4.

In summary, this study demonstrates for the first time that DP8 and DP9 are expressed in breast and ovarian carcinoma cell lines and suggests future investigations are required into understanding the complex interplay between the levels of DP9, DP4 and steroid hormone receptor status in breast and ovarian cancer. In addition, this study highlights the need for elucidating the mechanisms controlling transcription and post-transcriptional regulation of DP8, DP9, DP4 and FAP. Confirmation of our findings in clinical cancer samples is needed. Further investigations may identify novel DP specific pathways that can be targeted for the development of new treatments for breast and ovarian cancer.

\section{Acknowledgements}

We would like to thank Ms. Maressa Bruhn and Dr Karen Shephard (Peter Macallum Cancer Centre, Melbourne, Vic., Australia) for kindly providing us with the cells used in this study. Authors would also like to thank Dr Mark Gorrell (AW Morrow Gastroenteroogy and Liver Center, University of Sydney, NSW, Australia) for kindly providing hybridoma cells secreting the F19 monoclonal antibody.

\section{References}

1. Ferlay J, Shin HR, Bray F, Forman D, Mathers C and Parkin DM: Estimates of worldwide burden of cancer in 2008: GLOBOCAN 2008. Int J Cancer 127: 2893-2917, 2010.

2. Cho KR and Shih Ie M: Ovarian cancer. Annu Rev Pathol 4: 287-313, 2009.

3. Schnitt SJ: Classification and prognosis of invasive breast cancer: from morphology to molecular taxonomy. Mod Pathol 23 (Suppl 2): S60-S64, 2010.

4. Kurman RJ and Shih Ie M: Pathogenesis of ovarian cancer: lessons from morphology and molecular biology and their clinical implications. Int J Gynecol Pathol 27: 151-160, 2008.

5. Lambeir AM, Durinx C, Scharpe S and De Meester I: Dipeptidylpeptidase IV from bench to bedside: an update on structural properties, functions, and clinical aspects of the enzyme DPP IV. Crit Rev Clin Lab Sci 40: 209-294, 2003.

6. Bjelke JR, Christensen J, Nielsen PF, Branner S, Kanstrup AB, Wagtmann $N$ and Rasmussen HB: Dipeptidyl peptidases 8 and 9: specificity and molecular characterization compared with dipeptidyl peptidase IV. Biochem J 396: 391-399, 2006.

7. Ajami K, Pitman MR, Wilson CH, Park J, Menz RI, Starr AE, Cox JH, Abbott CA, Overall CM and Gorrell MD: Stromal cell-derived factors 1alpha and 1beta, inflammatory protein-10 and interferon-inducible $\mathrm{T}$ cell chemo-attractant are novel substrates of dipeptidyl peptidase 8. FEBS Lett 582: 819-825, 2008.

8. Keane FM, Nadvi NA, Yao TW and Gorrell MD: Neuropeptide Y, B-type natriuretic peptide, substance $\mathrm{P}$ and peptide $\mathrm{YY}$ are novel substrates of fibroblast activation protein-alpha. FEBS J 278: 1316-1332, 2011.

9. Busso N, Wagtmann N, Herling C, Chobaz-Peclat V, BischofDelaloye A, So A and Grouzmann E: Circulating CD26 is negatively associated with inflammation in human and experimental arthritis. Am J Pathol 166: 433-442, 2005.

10. Barbieri F, Bajetto A and Florio T: Role of chemokine network in the development and progression of ovarian cancer: a potential novel pharmacological target. J Oncol 2010: 426956, 2010.

11. Ali S and Lazennec G: Chemokines: novel targets for breast cancer metastasis. Cancer Metastasis Rev 26: 401-420, 2007.

12. Balkwill F: Cancer and the chemokine network. Nat Rev Cancer 4: 540-550, 2004.

13. Mentlein R: Dipeptidyl-peptidase IV (CD26): role in the inactivation of regulatory peptides. Regul Pept 85: 9-24, 1999. 
14. Sun YX, Pedersen EA, Shiozawa Y, Havens AM, Jung Y, Wang J, Pienta KJ and Taichman RS: CD26/dipeptidyl peptidase IV regulates prostate cancer metastasis by degrading SDF-1/ CXCL12. Clin Exp Metastasis 25: 765-776, 2008.

15. Arscott WT, La Bauve AE, May V and Wesley UV: Suppression of neuroblastoma growth by dipeptidyl peptidase IV: relevance of chemokine regulation and caspase activation. Oncogene 28: 479-491, 2009

16. Lu C, Tilan JU, Everhart L, Czarnecka M, Soldin SJ, Mendu DR, Jeha D, Hanafy J, Lee CK, Sun J, Izycka-Swiezczewska E, Toretsky JA and Kitlinska J: Dipeptidyl peptidases as survival factors in Ewing sarcoma family of tumors. J Biol Chem 286 27494-27505, 2011.

17. Yu DM, Wang XM, McCaughan GW and Gorrell MD: Extraenzymatic functions of the dipeptidyl peptidase IV-related proteins DP8 and DP9 in cell adhesion, migration and apoptosis. FEBS J 273: 2447-2460, 2006

18. Wang XM, Yu DM, McCaughan GW and Gorrell MD: Fibroblast activation protein increases apoptosis, cell adhesion, and migration by the LX-2 human stellate cell line. Hepatology 42: 935-945, 2005.

19. Sulda ML, Abbott CA and Hildebrandt M: DPIV/CD26 and FAP in cancer: a tale of contradictions. Adv Exp Med Biol 575 : 197-206, 2006

20. Johnson RC, Zhu D, Augustin-Voss HG and Pauli BU: Lung endothelial dipeptidyl peptidase IV is an adhesion molecule for lung-metastatic rat breast and prostate carcinoma cells. J Cell Biol 121: 1423-1432, 1993.

21. Cheng HC, Abdel-Ghany M, Elble RC and Pauli BU: Lung endothelial dipeptidyl peptidase IV promotes adhesion and metastasis of rat breast cancer cells via tumor cell surface-associated fibronectin. J Biol Chem 273: 24207-24215, 1998.

22. Cheng HC, Abdel-Ghany M, Zhang S and Pauli BU: Is the Fischer 344/CRJ rat a protein-knock-out model for dipeptidyl peptidase IV-mediated lung metastasis of breast cancer? Clin Exp Metastasis 17: 609-615, 1999.

23. Kajiyama H, Kikkawa F, Suzuki T, Shibata K, Ino K and Mizutani S: Prolonged survival and decreased invasive activity attributable to dipeptidyl peptidase IV overexpression in ovarian carcinoma. Cancer Res 62: 2753-2757, 2002.

24. Kajiyama H, Shibata K, Ino K, Mizutani S, Nawa A and Kikkawa F: The expression of dipeptidyl peptidase IV (DPPIV/ CD26) is associated with enhanced chemosensitivity to paclitaxel in epithelial ovarian carcinoma cells. Cancer Sci 101: 347-354, 2010.

25. Garin-Chesa P, Old LJ and Rettig WJ: Cell surface glycoprotein of reactive stromal fibroblasts as a potential antibody target in human epithelial cancers. Proc Natl Acad Sci USA 87: 7235-7239, 1990.

26. Chen D, Kennedy A, Wang JY, Zeng W, Zhao Q, Pearl M,Zhang M, Suo Z, Nesland JM, Qiao Y, Ng AK, Hirashima N, Yamane T, Mori Y, Mitsumata M, Ghersi G and Chen WT: Activation of EDTA-resistant gelatinases in malignant human tumors. Cancer Res 66: 9977-9985, 2006

27. Kraman M, Bambrough PJ, Arnold JN, Roberts EW, Magiera L, Jones JO, Gopinathan A, Tuveson DA and Fearon DT: Suppression of antitumor immunity by stromal cells expressing fibroblast activation protein-alpha. Science 330: 827-830, 2010.

28. Kelly T, Kechelava S, Rozypal TL, West KW and Korourian S Seprase, a membrane-bound protease, is overexpressed by invasive ductal carcinoma cells of human breast cancers. Mod Pathol 11: 855-863, 1998.

29. Ariga N, Sato E, Ohuchi N, Nagura H and Ohtani H: Stromal expression of fibroblast activation protein/seprase, a cell membrane serine proteinase and gelatinase, is associated with longer survival in patients with invasive ductal carcinoma of breast. Int J Cancer 95: 67-72, 2001.

30. Goodman JD, Rozypal TL and Kelly T: Seprase, a membranebound protease, alleviates the serum growth requirement of human breast cancer cells. Clin Exp Metastasis 20: 459-470, 2003

31. Huang Y, Wang S and Kelly T: Seprase promotes rapid tumor growth and increased microvessel density in a mouse model of human breast cancer. Cancer Res 64: 2712-2716, 2004.

32. Kennedy A, Dong H, Chen D and Chen WT: Elevation of seprase expression and promotion of an invasive phenotype by collagenous matrices in ovarian tumor cells. Int J Cancer 124: 27-35, 2009.

33. Abbott CA, Yu DM, Woollatt E, Sutherland GR, McCaughan GW and Gorrell MD: Cloning, expression and chromosomal localization of a novel human dipeptidyl peptidase (DPP) IV homolog, DPP8. Eur J Biochem 267: 6140-6150, 2000.
34. Yu DM, Yao TW, Chowdhury S, Nadvi NA, Osborne B, Church WB, McCaughan GW and Gorrell MD: The dipeptidyl peptidase IV family in cancer and cell biology. FEBS J 277: 1126-1144, 2010

35. Dubois V, Van Ginneken C, De Cock H, Lambeir AM, Van der Veken P, Augustyns K, Chen X, Scharpe S and De Meester I: Enzyme activity and immunohistochemical localization of dipeptidyl Peptidase 8 and 9 in male reproductive tissues. J Histochem Cytochem 57: 531-541, 2009.

36. Yao TW, Kim WS, Yu DM, Sharbeen G, McCaughan GW, Choi KY, Xia P and Gorrell MD: A novel role of dipeptidyl peptidase 9 in epidermal growth factor signaling. Mol Cancer Res 9: 948-959, 2011

37. Sulda ML, Abbott CA, Macardle PJ, Hall RK and Kuss BJ: Expression and prognostic assessment of dipeptidyl peptidase IV and related enzymes in B-cell chronic lymphocytic leukemia. Cancer Biol Ther 10: 180-189, 2010.

38. Yu DM, Ajami K, Gall MG, Park J, Lee CS, Evans KA, McLaughlin EA, Pitman MR, Abbott CA, McCaughan GW and Gorrell MD: The in vivo expression of dipeptidyl peptidases 8 and 9. J Histochem Cytochem 57: 1025-1040, 2009.

39. Stremenova J, Mares V, Lisa V, Hilser M, Krepela E, Vanickova Z, Syrucek M, Soula O and Sedo A: Expression of dipeptidyl peptidase-IV activity and/or structure homologs in human meningiomas. Int J Oncol 36: 351-358, 2010.

40. Stremenova J, Krepela E, Mares V, Trim J, Dbaly V, Marek J, Vanickova Z, Lisa V, Yea C and Sedo A: Expression and enzymatic activity of dipeptidyl peptidase-IV in human astrocytic tumours are associated with tumour grade. Int J Oncol 31: 785-792, 2007.

41. Soule HD, Vazguez J, Long A, Albert S and Brennan M: A human cell line from a pleural effusion derived from a breast carcinoma. J Natl Cancer Inst 51: 1409-1416, 1973.

42. Zajchowski DA, Bartholdi MF, Gong Y, Webster L, Liu HL, Munishkin A, Beauheim C, Harvey S, Ethier SP and Johnson PH: Identification of gene expression profiles that predict the aggressive behavior of breast cancer cells. Cancer Res 61: 5168-5178, 2001.

43. Crow MJ, Grant G, Provenzale JM and Wax A: Molecular imaging and quantitative measurement of epidermal growth factor receptor expression in live cancer cells using immunolabeled gold nanoparticles. AJR Am J Roentgenol 192: 1021-1028, 2009.

44. Lau KM, Mok SC and Ho SM: Expression of human estrogen receptor-alpha and -beta, progesterone receptor, and androgen receptor mRNA in normal and malignant ovarian epithelial cells. Proc Natl Acad Sci USA 96: 5722-5727, 1999.

45. Takai N, Jain A, Kawamata N, Popoviciu LM, Said JW, Whittaker S, Miyakawa I, Agus DB and Koeffler HP: 2C4, a monoclonal antibody against HER2, disrupts the HER kinase signaling pathway and inhibits ovarian carcinoma cell growth Cancer 104: 2701-2708, 2005.

46. Xu F, Yu Y, Le XF, Boyer C, Mills GB and Bast RC: The outcome of heregulin-induced activation of ovarian cancer cells depends on the relative levels of HER-2 and HER-3 expression. Clin Cancer Res 5: 3653-3660, 1999.

47. Hua W, Christianson T, Rougeot C, Rochefort $\mathrm{H}$ and Clinton GM: SKOV3 ovarian carcinoma cells have functional estrogen receptor but are growth-resistant to estrogen and antiestrogens. J Steroid Biochem Mol Biol 55: 279-289, 1995.

48. Hu G, Liu W, Mendelsohn J, Ellis LM, Radinsky R, Andreeff M and Deisseroth AB: Expression of epidermal growth factor receptor and human papillomavirus E6/E7 proteins in cervical carcinoma cells. J Natl Cancer Inst 89: 1271-1276, 1997.

49. Monje P and Boland R: Expression and cellular localization of naturally occurring beta estrogen receptors in uterine and mammary cell lines. J Cell Biochem 86: 136-144, 2002.

50. Lossos IS, Czerwinski DK, Wechser MA and Levy R: Optimization of quantitative real-time RT-PCR parameters for the study of lymphoid malignancies. Leukemia 17: 789-795, 2003.

51. Maes MB, Dubois V, Brandt I, Lambeir AM, Van der Veken P, Augustyns K, Cheng JD, Chen X, Scharpe S and De Meester I: Dipeptidyl peptidase 8/9-like activity in human leukocytes. J Leukocyte Biol 81: 1252-1257, 2007.

52. Abbott CA and Gorrell MD: The family of CD26/DPIV related ectopeptidases. In: Ectopeptidases: CD13/Aminopeptidase N and CD26/Dipeptidylpeptidase IV in Medicine and Biology. Langner $\mathbf{J}$ and Ansorge S (eds). Kluwer/Plenum, New York, pp171-195, 2002.

53. Balaziova E, Busek P, Stremenova J, Sromova L, Krepela E, Lizcova L and Sedo A: Coupled expression of dipeptidyl peptidase-IV and fibroblast activation protein-alpha in transformed astrocytic cells. Mol Cell Biochem 354: 283-289, 2011. 
54. Ajami K, Abbott CA, McCaughan GW and Gorrell MD: Dipeptidyl peptidase 9 has two forms, a broad tissue distribution, cytoplasmic localization and DPIV-like peptidase activity. Biochim Biophys Acta 1679: 18-28, 2004.

55. Pitman MR, Menz RI and Abbott CA: Hydrophilic residues surrounding the $\mathrm{S} 1$ and $\mathrm{S} 2$ pockets contribute to dimerisation and catalysis in human dipeptidyl peptidase 8 (DP8). Biol Chem 391: 959-972, 2010.

56. Bank U, Heimburg A, Wohlfarth A, Koch G, Nordhoff K, Julius H, Helmuth M, Breyer D, Reinhold D, Tager $M$ and Ansorge S: Outside or inside: role of the subcellular localization of DP4-like enzymes for substrate conversion and inhibitor effects. Biol Chem 392: 169-187, 2011.

57. Ansorge S, Nordhoff K, Bank U, Heimburg A, Julius H, Breyer D, Thielitz A, Reinhold D and Tager M: Novel aspects of cellular action of dipeptidyl peptidase IV/CD26. Biol Chem 392: 153-168, 2011.

58. Kikkawa F, Kajiyama H, Ino K, Shibata K and Mizutani S: Increased adhesion potency of ovarian carcinoma cells to mesothelial cells by overexpression of dipeptidyl peptidase IV. Int J Cancer 105: 779-783, 2003.

59. Huang Y, Simms AE, Mazur A, Wang S, Leon NR, Jones B, Aziz N and Kelly T: Fibroblast activation protein-alpha promotes tumor growth and invasion of breast cancer cells through nonenzymatic functions. Clin Exp Metastasis 28: 567-579, 2011.

60. Aertgeerts K, Levin I, Shi L, Snell GP, Jennings A, Prasad GS, Zhang Y, Kraus ML, Salakian S, Sridhar V, Wijnands R and Tennant MG: Structural and kinetic analysis of the substrate specificity of human fibroblast activation protein alpha. J Biol Chem 280: 19441-19444, 2005.

61. Chiravuri M, Agarraberes F, Mathieu SL, Lee H and Huber BT: Vesicular localization and characterization of a novel post-prolinecleaving aminodipeptidase, quiescent cell proline dipeptidase. J Immunol 165: 5695-5702, 2000.

62. Tang HK, Tang HY, Hsu SC, Chu YR, Chien $\mathrm{CH}$, Shu $\mathrm{CH}$ and Chen X: Biochemical properties and expression profile of human prolyl dipeptidase DPP9. Arch Biochem Biophys 485: 120-127, 2009.

63. Leiting B, Pryor KD, Wu JK, Marsilio F, Patel RA, Craik CS, Ellman JA, Cummings RT and Thornberry NA: Catalytic properties and inhibition of proline-specific dipeptidyl peptidases II, IV and VII. Biochem J 371: 525-532, 2003.

64. Maes MB, Martinet W, Schrijvers DM, Van der Veken P, De Meyer GR, Augustyns K, Lambeir AM, Scharpe S and De Meester I: Dipeptidyl peptidase II and leukocyte cell death. Biochem Pharmacol 72: 70-79, 2006.

65. Danilova O, Li B, Szardenings AK, Huber BT and Rosenblum JS: Synthesis and activity of a potent, specific azabicyclo[3.3.0]octane-based DPP II inhibitor. Bioorg Med Chem Lett 17: 507-510, 2007.
66. Hui M and Hui KS: A novel aminopeptidase with highest preference for lysine. Neurochem Res 31: 95-102, 2006.

67. Claperon C, Banegas-Font I, Iturrioz X, Rozenfeld R, Maigret B and Llorens-Cortes C: Identification of threonine 348 as a residue involved in aminopeptidase A substrate specificity. J Biol Chem 284: 10618-10626, 2009.

68. Fukasawa KM, Hirose J, Hata T and Ono Y: Aspartic acid 405 contributes to the substrate specificity of aminopeptidase B. Biochemistry 45: 11425-11431, 2006.

69. Drag M, Bogyo M, Ellman JA and Salvesen GS: Aminopeptidase fingerprints, an integrated approach for identification of good substrates and optimal inhibitors. J Biol Chem 285: 3310-3318, 2010.

70. Tenorio-Laranga J, Venalainen JI, Mannisto PT and GarciaHorsman JA: Characterization of membrane-bound prolyl endopeptidase from brain. FEBS J 275: 4415-4427, 2008.

71. Edosada CY, Quan C, Tran T, Pham V, Wiesmann C, Fairbrother W and Wolf BB: Peptide substrate profiling defines fibroblast activation protein as an endopeptidase of strict Gly(2)-Pro(1)-cleaving specificity. FEBS Lett 580: 1581-1586, 2006.

72. Cheng JQ, Lindsley CW, Cheng GZ, Yang H and Nicosia SV: The Akt/PKB pathway: molecular target for cancer drug discovery. Oncogene 24: 7482-7492, 2005.

73. Hernandez-Aya LF and Gonzalez-Angulo AM: Targeting the phosphatidylinositol 3-kinase signaling pathway in breast cancer. Oncologist 16: 404-414, 2011.

74. Zagouri F, Dimopoulos MA, Bournakis E and Papadimitriou CA: Molecular markers in epithelial ovarian cancer: their role in prognosis and therapy. Eur J Gynaecol Oncol 31: 268-277, 2010.

75. Mazzoletti M and Broggini M: PI3K/AKT/mTOR inhibitors in ovarian cancer. Curr Med Chem 17: 4433-4447, 2010.

76. Dickson RB, Thompson EW and Lippman ME: Regulation of proliferation, invasion and growth factor synthesis in breast cancer by steroids. J Steroid Biochem Mol Biol 37: 305-316, 1990.

77. Kim HJ, Cui X, Hilsenbeck SG and Lee AV: Progesterone receptor loss correlates with human epidermal growth factor receptor 2 overexpression in estrogen receptor-positive breast cancer. Clin Cancer Res 12: S1013-S1018, 2006

78. Yager JD and Davidson NE: Estrogen carcinogenesis in breast cancer. N Engl J Med 354: 270-282, 2006.

79. Oakman C, Viale G and Di Leo A: Management of triple negative breast cancer. Breast 19: 312-321, 2010.

80. Rao BR, Slotman BJ, Geldof AA and Dinjens WN: Correlation between tumor histology, steroid receptor status, and adenosine deaminase complexing protein immunoreactivity in ovarian cancer. Int J Gynecol Pathol 9: 47-54, 1990. 